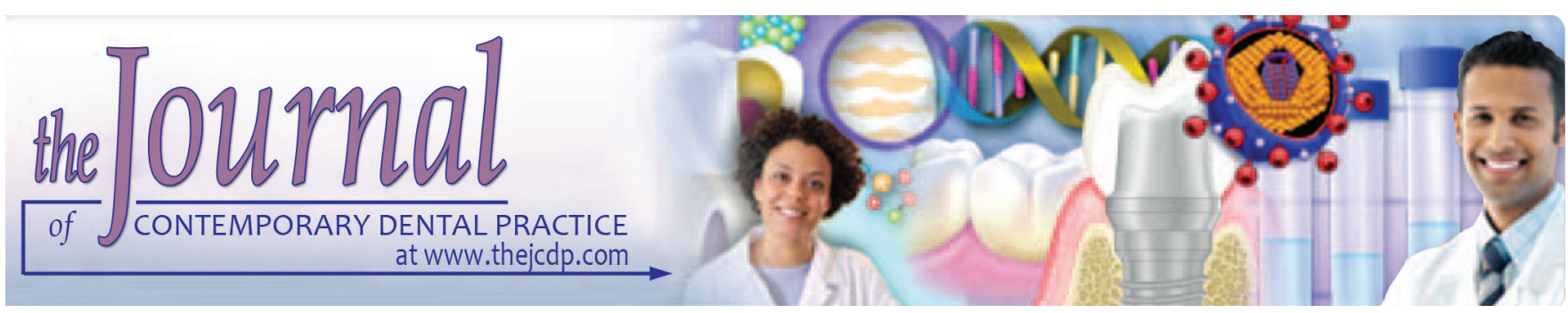

\title{
Effects of Different Stain Removal Protocols on Bonding Orthodontic Brackets to Enamel
}

\author{
${ }^{1}$ Ibrahim Alshahrani, ${ }^{2}$ Khalid Abdelaziz, ${ }^{3}$ Moshabab A Asiry, ${ }^{4}$ Al Jowharah A Al AIShikh \\ ${ }^{5}$ Wala AIGhamdi, ${ }^{6}$ Hajer A Mansour
}

\section{ABSTRACT}

Aim: To evaluate the effect of different stain removal protocols with or without topical fluoride application on the bond strength of orthodontic brackets to enamel.

Materials and methods: Eighty extracted premolars were randomly assigned into four groups according to the stain removal protocol. The stain removal protocols were (1) using rubber cup with prophylaxis paste in $(\mathrm{G} 1, \mathrm{n}=20),(2)$ air-abrasion with prophy-jet polishing system ( $G 2, n=20)$, (3) micro-abrasion with opalusture polishing paste $(G 3, n=20)$, and (4) macroabrasion with ultrafine diamond finishing tips $(G 4, n=20)$. Ten teeth in each group (SG1, $n=10$ ) had no topical fluoride treatment after stain removal protocol, while the rest $(S G 2, n=10)$ were subjected to topical fluoride application. After bonding the orthodontic brackets, all specimens were thermocycled before testing their bracket-enamel bond strength. The debonded bracket and enamel surfaces of each specimen were also assessed to determine the adhesive remnant index (ARI) for each subgroup.

Results: Specimens in G2, G3, and G4 recorded lower shear bond strength as compared with $\mathrm{G} 1(\mathrm{p}<0.05)$. For all groups, specimens in SG2 demonstrated lower bond strength than their counterpart in SG1 $(p<0.05)$. No significant differences were detected between the ARIs of different subgroups $(p>0.05)$.

Conclusion: Bonding orthodontic brackets is affected by the protocol of removing enamel stains. The use of the rubber cup

\footnotetext{
1,4-6 Department of Pediatric Dentistry and Orthodontics, King Khalid University, Abha, Kingdom of Saudi Arabia

${ }^{2}$ Department of Restorative Dental Sciences, King Khalid University, Abha, Kingdom of Saudi Arabia

${ }^{3}$ Department of Pediatric Dentistry and Orthodontics, College of Dentistry, King Saud University, Riyadh, Kingdom of Saudi Arabia

Corresponding Author: Moshabab A Asiry, Department of Pediatric Dentistry and Orthodontics, College of Dentistry, King Saud University, Riyadh, Kingdom of Saudi Arabia, e-mail: masiry@gmail.com
}

with prophylaxis paste provided the highest bracket-ename bond strength. Topical fluoride application usually complicates the bonding process of orthodontic brackets to cleaned enamel surfaces.

Clinical significance: The results of the current study indicate higher bracket bond strength to enamel surfaces treated with different stain removal protocols than the clinically acceptable values (5.9-7.8 MPa). However, the more aggressive enamel pretreatment methods should not be considered unless the clinical situation necessitates such action. Postponing the topical fluoride application is advisable to follow the bracket bonding procedure. This action would prevent the negative effect of topical fluorides on bracket-enamel bond strength.

Keywords: Bonding, Micro-abrasion, Stain removal, Thermocycling, Topical fluoride.

How to cite this article: Alshahrani I, Abdelaziz K, Asiry MA, Al AIShikh AJA, AIGhamdi W, Mansour HA. Effects of Different Stain Removal Protocols on Bonding Orthodontic Brackets to Enamel. J Contemp Dent Pract 2018;19(7):762-767.

Source of support: Nil

Conflict of interest: None

\section{INTRODUCTION}

Removal of enamel surface deposits and superficial stains usually provides healthy oral environment and helps achieve durable orthodontic bracket bonding. ${ }^{1}$ Many stain removal protocols are utilized to efficiently cleanse and remove stains from the superficial enamel layers prior to bonding of orthodontic brackets. ${ }^{2-4}$ Tooth polishing using the prophylaxis paste is considered a routine oral hygiene measure that would help removal of enamel surface stains. ${ }^{5}$ However, the aggressive application of this technique or even the utilization of coarse prophylaxis pastes could lead to damage of the outermost enamel layer that normally take 3 months to be remineralized back. ${ }^{6,7}$ Currently, the popularity of air-powder polishers has been increased in response to its ability to remove the supragingival plaque and stains in areas 
not accessible by other rotary devices. This method was reported to provide efficient plaque removal around the bonded orthodontic appliances with no damage to the bonded components. ${ }^{8-10}$

Although other techniques, such as micro-abrasion, macro-abrasion, and bleaching are currently popular for removing intrinsic and fluorotic stains, none is considered successful in removing all kind of stains or that suits patients' specific situations. ${ }^{11}$ Micro-abrasion is used to manage superficial enamel stains no more than 0.2 to $0.3 \mathrm{~mm}$ deep, those usually noticed in association with hypoplastic spots, postorthodontic demineralization, and fluorosis. A hydrochloric acid abrasive paste is usually agitated using rubber polishing cups against the affected enamel surfaces. This action combines both chemical erosion and physical abrasion of $360 \pm 130 \mu \mathrm{m}$ of the outer enamel layer. ${ }^{12,13}$ Macro-abrasion is an alternative technique that utilizes composite finishing burs or fine grit diamonds in high-speed handpiece with air-water cooling to remove the localized superficial white spots and stains out of enamel surfaces. ${ }^{14}$ This fast and safe technique does not require rubber dam or special instrumentation, although it may result in catastrophic enamel removal if the operator fails to pay enough attention. ${ }^{15}$

These prophylactic and stain removal protocols to some extent could alter enamel's surface topography. Therefore, they may followed by topical fluoride application to ensure enamel protection and re-mineralization. ${ }^{15-17}$ However, due to the expected influence of these procedures on enamel surface characteristics and its wetting with liquid adhesives, a strong thought is that such preparatory measures could influence the bonding values of the orthodontic resin adhesives to enamel surfaces. ${ }^{16,18-21}$ The aim of the present study was to evaluate the effect of different stain removal protocols and the topical fluoride application on the bond strength of orthodontic brackets to human tooth enamel.

\section{MATERIALS AND METHODS}

The present study was approved by the Institutional Ethical Committee at the College of Dentistry, King Khalid University, Abha, Kingdom of Saudi Arabia. A total of 80 freshly extracted, caries-free maxillary premolars were collected from patients undergoing orthodontic treatment. The collected teeth were stored in distilled water at $4^{\circ} \mathrm{C}$ for not more than 1 month before their use in the study. The teeth were randomly assigned into four different groups according to the stain removal protocol followed. Teeth in group I $(G 1, n=20)$ were mechanically polished for 60 seconds using prophylaxis paste (Qartz, DAHARMA Research Inc, Miami, FL) with regular polishing rubber cups (DENTAMERICA Asia
Inc, Taipei, Taiwan) rotating at slow speed in presence of air-water cooling. Teeth in group II $(G 2, n=20)$ were air polished for 60 seconds with an aluminum trihydroxide slurry (Jet-Fresh Prophy Powder, Dentsply Sirona, York, PA) using the Prophy-Jet air-polishing device (Cavitron Jet Plus, Dentsply Professional, York, PA). To get the optimum efficiency, the device nozzle was held $4 \mathrm{~mm}$ away directed at $60^{\circ}$ angle on the midthird of teeth surfaces. Teeth in group III $(G 3, n=20)$ were treated with a modified micro-abrasion technique using a paste of silicone carbide microparticles and 6.6\% hydrochloric acid (Opalusture, Ultradent Products, Jordan). The paste was rotated against the tooth surfaces for 60 seconds using rubber polishing cups. In group IV (G4, n=12), the buccal surfaces of teeth were subjected to a macro-abrasion process using ultrafine composite finishing diamond tips (\#SE6, White, Lakewood, NJ). These tips were rotated for 30 seconds in high speed under air-water cooling against enamel surfaces using gentle, intermittent pressure. White abrasive rubber points (Jazz polisher, White, Lakewood, NJ) were then used to finalize the macro-abrasion procedure. The treated teeth in all groups, regardless of the utilized enamel pretreatment protocol, were meticulously washed-up using continuous stream of air-water spray for 30 seconds and air dried for additional 30 seconds. Before bonding the orthodontic brackets, half the number of teeth in each group received no further treatment (SG1, $n=10)$, while the other half (SG2, n = 10) were subjected to topical fluoride application. The sodium fluoride gel (Flor-Opal, Ultradent Products, Jordan) was applied against the buccal surface of each tooth and left undisturbed for 4 minutes before washing-up and air drying.

The metal orthodontic brackets (Victory series, 3M/ Unitek, Monrovia, CA) were bonded to the treated surfaces by using traditional etch-and-bond resin adhesives (Transbond XT, 3M Unitek, Monrovia, CA). Prior to bonding, the enamel surface was etched with phosphoric acid for 15 seconds, washed up, and dried before agitating two coats of the Transbond XT adhesive primer. The applied primer was light-cured for 10 seconds using Elipar S10 (3M ESPE, Seefeld, Germany) light-curing device. A thin layer of adhesive was then applied on base of each bracket before positioning against the cured primer. The adhesive was then light-cured for 20 seconds from each side of the bracket. After bonding the orthodontic brackets, all specimens were thermocycled for 1,500 cycles at 5 to $55^{\circ} \mathrm{C}$ with 1-minute dwell time (Huber 1100, SD Mechatronik, Feldkirchen Westerham, Germany). The bracket-enamel bond strength was then tested on a universal testing machine (Instron Corporation, Canton, Massachusetts, USA) by the aid of knife-edged rod running at a crosshead speed of $0.5 \mathrm{~mm} / \mathrm{min}$ and directed at the bracket-tooth interface. The shear bond 
strength of each specimen was electronically calculated in MPa utilizing the operating software of the universal testing machine.

The debonded bracket and enamel surface of each tested specimen were also assessed using a light stereomicroscope (Nikon SM2-10, Tokyo, Japan) at $\times 20$ magnification to determine the $\mathrm{ARI}^{22}$ for each subgroup. The amount of adhesive remnants on tooth enamel surface was scored 0 when a total separation at adhesive-tooth interface was detected and no adhesive remained bonded to tooth enamel; 1 when partial separation at adhesive-tooth interface was detected and less than $50 \%$ of the adhesive remained bonded to tooth enamel; 2 when partial separation at adhesive-tooth interface was detected and more than $50 \%$ of the adhesive remained bonded to tooth enamel; and 3 when total separation at adhesive-bracket interface was detected and the whole amount of the adhesive remained bonded to tooth enamel.

The data obtained were analyzed by Statistical Package for Social Sciences version 18.0 (SPSS Inc., Chicago, Illinois). The bond strength data were analyzed using two-way analysis of variance and Tukey's pairwise comparisons at $\alpha=0.05$. The recorded adhesive remnants scores were analyzed using chi-squared test $\left(\chi^{2}\right)$ at $\alpha=0.05$ to detect any significant differences between subgroups.

\section{RESULTS}

The mean shear bond strength values (MPa) with standard deviations for all test subgroups are presented in Table 1. In SG1 subgroups (no fluoride treatment), bond strength values were not significantly different between specimens managed with micro-abrasion (G3) and those managed with macro-abrasion (G4), although both groups showed significantly lower bond strength values than those managed respectively, with mechanical brushing (G1) and air-abrasion (G2) ( $\mathrm{p}<0.05)$. For all groups, specimens of SG2 (fluoride-treated) showed significantly lower bond strength values than their counterparts of SG1 $(p<0.05)$. The Tukey's pairwise comparisons between different subgroups showed higher bond strength value of mechanical brushing (G1) with no fluoride treatment in comparison with all SG1 and SG2 subgroups $(\mathrm{p}<0.05)$.

Table 2 shows the incidences (\%) of bond failure scores in different subgroups. The chi-squared $\left(\chi^{2}\right)$ test revealed no statistical differences between test subgroups ( $p>0.05)$, although variable incidences of different adhesive remnant scores were obvious in all test subgroups.

\section{DISCUSSION}

Presence of either extrinsic or intrinsic stains usually interferes with the proper bonding of bracket to tooth enamel. Extrinsic stains usually prevent the proper interaction of adhesive material with the outermost layer of tooth enamel, while the increased amount of organic matrix which is a characteristic feature in some cases of discolored tooth enamel seems responsible for the inadequate adhesive bonding of dental restoratives and adhesives. ${ }^{23}$ On the contrary, the higher fluoride content renders the outer surfaces of the fluorotic teeth poorly reactive and sometimes resistant to acid etching. ${ }^{16}$ Several stain

Table 1: Mean bond strength values (MPa) in different subgroups

\begin{tabular}{lllll}
\hline & \multicolumn{4}{c}{ Stain removal methods (groups) } \\
\cline { 2 - 5 } Subgroups & Rubber cup prophylaxis (G1) & Air-abrasion (G2) & Micro-abrasion (G3) & Macro-abrasion (G4) \\
\hline No topical fluoride (SG1) & $11.62 \pm 0.39^{\mathrm{a} 1}$ & $9.94 \pm 0.14^{\mathrm{a} 2}$ & $9.27 \pm 0.14^{\mathrm{a} 3}$ & $9.45 \pm 0.20^{\mathrm{a} 3}$ \\
Topical fluoride (SG2) & $10.36 \pm 0.21^{\mathrm{b} 1}$ & $9.32 \pm 0.11^{\mathrm{b} 2}$ & $6.96 \pm 0.08^{\mathrm{b} 3}$ & $8.94 \pm 0.34^{\mathrm{b} 4}$ \\
\hline
\end{tabular}

Different superscript letters within columns (groups) indicate significant difference between subgroups $(p<0.05)$; different superscript numbers within rows (subgroups) indicate significant difference between groups $(p<0.05)$

Table 2: Incidences (\%) of adhesive remnant scores in different subgroups

\begin{tabular}{|c|c|c|c|c|c|c|c|c|}
\hline \multirow{3}{*}{$\begin{array}{l}\text { Adhesive } \\
\text { remnant } \\
\text { scores }\end{array}$} & \multicolumn{8}{|c|}{ Enamel pretreatment methods (groups) } \\
\hline & \multicolumn{2}{|c|}{ Rubber cup prophylaxis (G1) } & \multicolumn{2}{|c|}{ Air-abrasion (G2) } & \multicolumn{2}{|c|}{ Micro-abrasion (G3) } & \multicolumn{2}{|c|}{ Macro-abrasion (G4) } \\
\hline & $\begin{array}{l}\text { No fluoride } \\
\text { (SG1) }\end{array}$ & $\begin{array}{l}\text { Fluoride } \\
\text { (SG2) }\end{array}$ & $\begin{array}{l}\text { No fluoride } \\
\text { (SG1) }\end{array}$ & $\begin{array}{l}\text { Fluoride } \\
\text { (SG2) }\end{array}$ & $\begin{array}{l}\text { No fluoride } \\
\text { (SG1) }\end{array}$ & $\begin{array}{l}\text { Fluoride } \\
\text { (SG2) }\end{array}$ & $\begin{array}{l}\text { No fluoride } \\
\text { (SG1) }\end{array}$ & $\begin{array}{l}\text { Fluoride } \\
\text { (SG2) }\end{array}$ \\
\hline Score 0 & $0.0 \%$ & $20.0 \%$ & $30.0 \%$ & $40.0 \%$ & $30.0 \%$ & $40.0 \%$ & $30.0 \%$ & $40.0 \%$ \\
\hline Score 1 & $30.0 \%$ & $20.0 \%$ & $40.0 \%$ & $30.0 \%$ & $30.0 \%$ & $30.0 \%$ & $50.0 \%$ & $30.0 \%$ \\
\hline Score 2 & $30.0 \%$ & $30.0 \%$ & $20.0 \%$ & $30.0 \%$ & $20.0 \%$ & $20.0 \%$ & $10.0 \%$ & $20.0 \%$ \\
\hline Score 3 & $40.0 \%$ & $30.0 \%$ & $10.0 \%$ & $0.0 \%$ & $20.0 \%$ & $20.0 \%$ & $10.0 \%$ & $0.0 \%$ \\
\hline ARI & $2.1 \pm 0.88$ & $1.7 \pm 1.16$ & $1.1 \pm 0.99$ & $0.90 \pm 0.88$ & $1.3 \pm 1.16$ & $0.9 \pm 0.88$ & $1.0 \pm 0.94$ & $0.9 \pm 0.88$ \\
\hline
\end{tabular}

Score 0: No adhesive remained on enamel surface; Score 1: less than $50 \%$ of the adhesive remained on enamel surface; Score 2 : More than $50 \%$ of the adhesive remained on enamel surface; Score 3: the total amount of adhesive remained on enamel surface; ARI: Adhesive remnant index $\left(\chi^{2}=11.21\right.$ between subgroups); Higher ARI values indicate higher amounts of adhesive that remained bonded to tooth enamel 
removal protocols accordingly have been recommended to obtain enamel surfaces suitable for adhesive bonding of the orthodontic brackets. ${ }^{1-4}$ However, topical fluoride application can be recommended to ensure enamel protection and re-mineralization after altering the enamel surface as a result of the prophylactic and enamel pretreatment protocols. ${ }^{5,6}$ The present study evaluated the bond strength of orthodontic brackets bonded to enamel surfaces treated with different stain removal protocols either with or without fluoride application.

Enamel surfaces polished using rubber cup and prophylaxis paste (G1) provided the highest brackets' bond strength values when compared with those treated with air-abrasion, micro-abrasion, and macro-abrasion. Results of Shobbana Devi et $\mathrm{al}^{24}$ also showed higher brackets' bond strength to enamel polished with rubber cup prophylaxis when compared with the unpolished enamel. These findings could be explained by the efficient removal of stains from the outermost enamel layer using a more conservative cleaning procedure leaving minimal damage to enamel's inorganic contents, and this surely reflects on the success of the acid-etching procedure. This explanation is indirectly supported by Yudaguven et al, ${ }^{7}$ who reported minimal damage of enamel surfaces after polishing using the prophylaxis paste. Furthermore, Osorio et $\mathrm{al}^{25}$ reported an increase in the surface energy of enamel surfaces subjected to rubber cup prophylaxis polishing. This alteration in enamel's surface properties would provide better wetting with the phosphoric acid and, accordingly, allow for the desirable etching action.

Air-abrasion/jet polishing was known to be more effective in removing surface biofilm and stains than rubber cup prophylactic polishing, especially in areas not accessible by the cup or brush. ${ }^{26}$ Although the use of sodium bicarbonate particles is highly recommended to achieve the air-abrasion action, the harder aluminum trihydroxide particles alternatively can be used with patients going on sodium-restricted diets. The pressurized bombarding of enamel surface with this type of particles postulates a noticeable surface abrasion and debris layer formation. ${ }^{27,28}$ These features could interfere with the appropriate etching and the subsequent wetting of the liquid to enamel surfaces. ${ }^{25}$ The result of the current study is in agreement with the aforementioned postulation as decreased bond strength was obvious for group II specimens as compared with those of group I. On the contrary, Gerbo et $\mathrm{al}^{29}$ showed no difference in the bond strength data of the rubber cup-polished and air-abraded enamel surfaces. Sengun et $\mathrm{al}^{16}$ also reported no difference in the bond strength between air-abraded and nonabraded enamel surfaces when a total-etch adhesive was used for the bonding purpose. The conflict between the results of those studies and the results of the current study could be referred to the differences in the study design and the types of the abrasives and adhesives used.

In the results of this study, the micro-abraded enamel surfaces (G3) provided lower bond strength than the rubber cup-polished (G1), air-abraded (G2), and macroabraded (G4) enamel surfaces. This finding could be explained based on the statement of Gerbo et $\mathrm{al}^{29}$ that the double exposure of the tooth to acid may significantly lower the bond strength of the resin adhesives. Elongating the exposure time to acids may result in overetching and widening of the created irregularities. The developed roughness may, in turn, result in air pockets, which interfere with the appropriate wetting of enamel surfaces with the liquid adhesive. ${ }^{7}$ Bassir et $\mathrm{al}^{30}$ revealed an adverse effect of micro-abrasion on the bond strength of resin adhesive to either normal or fluorosed enamel surfaces. They referred their results to the alteration in enamel surface structure caused by micro-abrasion. Micro-abrasion normally reduces the superficial enamel thickness yielding a densely mineralized, prism-free, and acid-resistant layer that could be responsible for the lower surface reactivity to the etching acid and the lower wettability of the liquid adhesive. ${ }^{31,32}$

The results of the current study showed that the bond strength of macro-abraded (G4) enamel surfaces ranked third after that of the air-abraded (G2) enamel surfaces. However, Van Meerbeek et $\mathrm{al}^{21}$ reported similar bond strength values of resin adhesives to air-abraded and diamond bur-abraded (macro-abraded) enamel surfaces. In addition, Sengun et $\mathrm{al}^{16}$ revealed no significant differences in bond strength values of resin to enamel following either air- or bur-abrasion. The outermost enamel layer usually shows low reactivity and resistance to acid etching in presence of organic biofilms, and higher fluoride content. Therefore, cutting through the enamel thickness had been suggested to overcome such problems. However, the cutting procedure can only remove the deposited biofilm but, at the same time, cannot increase enamel's surface energy as a result of smear layer deposition. ${ }^{16}$

On the contrary, the application of topical fluoride after the prophylactic and stain removal procedures has been proposed to enhance the re-mineralization and the resistance of the treated enamel to acid dissolution. ${ }^{15,33}$ However, the formed fluoride-enamel reaction products $^{34}$ was proved to reduce the bonding efficacy of resin adhesives to enamel surfaces. ${ }^{18,35}$ This statement could be applied to explain the noticeable reduction in the bond strength values of the four tested subgroups when the orthodontic brackets were adhesively bonded to tooth enamel following the stain removal and fluoride application procedures. Bryant et $\mathrm{al}^{36}$ applied different topical fluoride agents to the enamel surfaces of extracted central incisors after their mechanical abrasion. The fluoridated 
surfaces were then subjected to 1-min etching before bonding of orthodontic brackets. Their results revealed no influence of the applied fluoride on the tested bracket bond strength. The contradiction between their results and those of the current study could be referred to the different fluoride application and washing-up protocols and to the different etching times utilized in either study. Another study ${ }^{37}$ demonstrated that the application of fluoride to enamel surfaces negatively affects the bond strength of resinous materials even after mechanical polishing of the treated surfaces. Both Meng et $\mathrm{al}^{38}$ and Barcroft et al ${ }^{39}$ also proved an adverse effect of topical application of different fluoride preparations on orthodontic bracket bond strength to acid-eroded enamel surfaces. Findings of the aforementioned studies support the findings of the current study and none of the reviewed studies deny the negative role of fluoridating sound and prepared enamel surfaces with regard to the bond strength of resin-based materials.

No statistically significant differences were found between the ARIs of all subgroups. However, higher incidences (\%) of adhesive remnants were obvious in the tested G1 specimens. This could be a reflection of the highest bracket-enamel bond strengths of G1 specimens in comparison with other groups. This finding is in line with the results of other studies, ${ }^{40-42}$ which indicated higher ARI in association with the higher bracket-enamel bond strength

In summary, the results of the current study revealed higher bracket bond strength to enamel surfaces treated with different stain removal protocols than the clinically acceptable values (5.9-7.8 MPa). ${ }^{43}$ However, orthodontists should also pay attention to the following clinical highlights: (1) The more aggressive enamel pretreatment methods should not be considered unless the clinical situation necessitates such action, (2) Bonding orthodontic bracket immediately after the stain removal procedure is highly recommended and postponing the topical fluoride application to follow the bracket bonding procedure is accordingly advisable. Assessment of the quality of bracket bonding to polished enamel surfaces is also recommended for further study when different types of adhesives are used to achieve adhesive bonding.

\section{CONCLUSION}

Bonding orthodontic brackets is affected by the protocol of stain removal. The use of the mechanical brushing with prophylaxis paste technique provided the highest bracket-enamel bond strength. Topical fluoride application usually complicates the bonding process of orthodontic brackets to the cleaned enamel surfaces.

\section{REFERENCES}

1. Cooper JR 3rd, Young NB, Haywood VB, Mettenburg D, Callan RS, Rueggeberg FA. Effect of short-duration, localized carbamide peroxide application to remove enamel staining on bond strength of resin cement to enamel. J Esthetic Restor Dent 2016 May;28(3):190-196.

2. Kalili T, Caputo AA, Mito R, Sperbeck G, Matyas J. In vitro toothbrush abrasion and bond strength of bleached enamel. Pract Periodontics Aesthet Dent 1991 Aug;3(5):22-24.

3. Johnston CD, McSherry PF. The effects of sandblasting on the bond strength of molar attachments-an in vitro study. Eur J Orthod 1999 Jun;21(3):311-317.

4. Heravi F, Shafaee H, Abdollahi M, Rashed R. How is the enamel affected by different orthodontic bonding agents and polishing techniques? J Dent (Tehran) 2015 Mar;12(3):188-194.

5. Lutz F, Sener B, Imfeld T, Barbakow F, Schüpbach P. Selfadjusting abrasiveness: a new technology for prophylaxis pastes. Quintessence Int 1993 Jan;24(1):53-63.

6. Sawai MA, Bhardwaj A, Jafri Z, Sultan N, Daing A. Tooth polishing: the current status. J Indian Soc Periodontol 2015 Jul-Aug;19(4):375-380.

7. Yurdaguven H, Aykor A, Ozel E, Sabuncu H, Soyman M. Influence of a prophylaxis paste on surface roughness of different composites, porcelain, enamel and dentin surfaces. Eur J Dent 2012 Jan;6(1):1-8.

8. Boyde A. Airpolishing effects on enamel, dentine, cement and bone. Br Dent J 1984 Apr;156(8):287-291.

9. Galloway SE, Pashley DH. Rate of removal of root structure by the use of the Prophy-Jet device. J Periodontol 1987 Jul;58(7):464-469.

10. Barnes CM, Russel CM, Gerbol LR, Wells BR, Barnes DW. Effects of an air powder polishing system on orthodontically bracketed and banded teeth. Am J Orthod Dentofacial Orthop 1990 Jan;97(1):74-81.

11. Benbachir N, Ardu S, Krejci I. Spectrophotometric evaluation of the efficacy of a new in-office bleaching technique. Quintessence Int 2008 Apr;39(4):299-306.

12. Murphy TC, Willmot DR, Rodd HD. Management of postorthodontic demineralized white lesions with microabrasion: a quantitative assessment. Am J Orthod Dentofacial Orthop 2007 Jan;131(1):27-33.

13. Tong LS, Pang MK, Mok NY, King NM, Wei SH. The effect of etching, micro-abrasion and bleaching on surface enamel. J Dent Res 1993 Jan;72(1):67-71.

14. Amarlal D, Rayen R, Muthu MS. Macroabrasion in pediatric dentistry. J Clin Pediatr Dent 2006 Fall;31(1):9-13.

15. Heymann, HO. Additional conservative esthetic procedure. In: Heymann HO, Swift EJ, Ritter AV, editors. Sturdevant's art and science of operative dentistry. 6th ed. St. Louis (MO): Elsevier Science; 2013. pp. 296-338.

16. Sengun A, Orucoglu H, Ipekdal I, Ozer F. Adhesion of two bonding systems to air-abraded or bur-abraded human enamel surfaces. Eur J Dent 2008 Jul;2:167-175.

17. Khoroushi M, Kachuie M. Prevention and treatment of white spot lesions in orthodontic patients. Contemp Clin Dent 2017 Jan-Mar;8(1):11-19.

18. VelI I, Akin M, Baka ZM, Uysal T. Effects of different pretreatment methods on the shear bond strength of orthodontic brackets to demineralized enamel. Acta Odontol Scand 2016;74(1):7-13.

19. Montasser MA, El-Wassefy NA, Taha M. In vitro study of the potential protection of sound enamel against demineralization. Prog Orthod 2015 May;16:12.

20. Roeder LB, Berry EA 3rd, You C, Powers JM. Bond strength of composite to air-abraded enamel and dentin. Oper Dent 1995 Sep-Oct;20(5):186-190. 
21. Van Meerbeek B, De Munck J, Mattar D, Van Landuyt K, Lambrechts P. Microtensile bond strengths of an etch\&rinse and self-etch adhesive to enamel and dentin as a function of surface treatment. Oper Dent 2003 Sep-Oct;28(5):647-660.

22. Ryou DB, Park HS, Kim KH, Kwon TY. Use of flowable composites for orthodontic bracket bonding. Angle Orthod 2008 Nov;78(6):1105-1109.

23. Yadav S, Yadav H, Arora S. Removal of intrinsic stains from vital teeth by a combination therapy-Case reports. Indian J Dent Sci 2013 Mar;5(1):58-61.

24. Shobbana Devi VR, Anand MK, Venkateswaran S, Iyer KS, Krishnaswamy NR. Comparison of shear bond strength of selfetching fluoride releasing adhesives with and without pumice prophylaxis. Indian J Dent Res 2015 Jul-Aug;26(4):390-395.

25. Osorio R, Toledano M, Cabrerizo-Vílchez MA, Rosales JI, Bravo M, Osorio E. Influence of enamel prophylaxis on wettability of three commercially available orthophosphoric acids. J Biomed Mater Res 1996 Winter;33(4):269-274.

26. Graumann SJ, Sensat ML, Stoltenberg JL. Air polishing: a review of current literature. J Dent Hyg 2013 Aug;87(4):173-180.

27. Johnson WW, Barnes CM, Covey DA, Walker MP, Ross JA. The effects of a commercial aluminum air polishing powder on dental restorative materials. J Prosthodont 2004 Sep;13(3): 166-172.

28. Barnes CM, Covey D, Watanabe H, Simetich B, Schulte JR, Chen $\mathrm{H}$. An in vitro comparison of the effects of various air polishing powders on enamel and selected esthetic restorative materials. J Clin Dent 2014;25(4):76-87.

29. Gerbo LR, Lacefield WR, Wells BR, Russell CM. The effect of enamel preparation on the tensile bond strength of orthodontic composite resin. Angle Orthod 1992 Dec;62(4):275-281.

30. Bassir MM, Rezvani MB, Ghomsheh ET, Hosseini ZM. Effect of different surface treatments on microtensile bond strength of composite resin to normal and fluorotic enamel after microabrasion. J Dent (Tehran) 2016 Nov;13(6):431-437.

31. Donly KJ, O'Neill M, Croll TP. Enamel microabrasion: a microscope evaluation of the "abrasion effect". Quintessence Int 1992 Apr;23(3):175-179.
32. Croll TP, Segura A, Donly KJ. Enamel microabrasion: new consideration in 1993. Pract Periodontics Aesthet Dent 1993 Oct;5(8):19-28.

33. Koulourides T, Keller SE, Manson-Hing L, Lilley V. Enhancement of fluoride effectiveness by experimental cariogenic priming of human enamel. Caries Res 1980;14(1):32-39.

34. Richardson B. Fixation of topically applied fluoride in enamel. J Dent Res 1967 Jan-Feb;46(1):84-91.

35. Leodido Gda R, Fernandes HO, Tonetto MR, Presoto CD, Bandéca MC, Firoozmand LM. Effect of fluoride solutions on the shear bond strength of orthodontic brackets. Braz Dent J 2012;23(6):698-702.

36. Bryant S, Retief DH, Bradley EL Jr, Denys FR. The effect of topical fluoride treatment on enamel fluoride uptake and the tensile bond strength of an orthodontic bonding resin. Am J Orthod 1985 Apr;87(4):294-302.

37. Frazer RA, Platt JA, Sanders BJ, Yepes JF, Jones JE. The effect of fluoride varnish on enamel shear bond strength of pit and fissure sealants. Pediatr Dent 2017 Mar;39(2):155-158.

38. Meng CL, Li CH, Wang WN. Bond strength with APF applied after acid etching. Am J Orthod Dentofacial Orthop 1998 Nov;114(5):510-513.

39. Barcroft BD, Childers KR, Harris EF. Effects of acidulated and neutral NaF solutions on bond strengths. Pediatr Dent 1990 May-Jun;12(3):180-182.

40. Elnafar AA, Alam MK, Hasan R. The impact of surface preparation on shear bond strength of metallic orthodontic brackets bonded with a resin-modified glass ionomer cement. J Orthod 2014 Sep;41(3):201-207.

41. Suma S, Anita G, Chandra Shekar BR, Kallury A. The effect of air abrasion on the retention of metallic brackets bonded to fluorosed enamel surface. Indian J Dent Res 2012 Mar-Apr;23(2):230-235.

42. Charles A, Senkutvan R, Ramya RS, Jacob S. Evaluation of shear bond strength with different enamel pretreatments: an in vitro study. Indian J Dent Res 2014 Jul-Aug;25(4):470-474.

43. Reynolds IR. A review of direct orthodontic bonding. Br J Orthod 1975 Jul;2(3):171-178. 